Annals of Plant and Soil Research 23(2): 129-134 (2021)

https://doi.org/10.47815/apsr.2021.10044

\title{
In vitro effect of chromium, lead and manganese on seed germination, growth and mineral composition of finger millet (Eleusine coracana)
}

\author{
DUDDELA VARAPRASAD ${ }^{\dagger}$, MERUVA KEERTHI KUMARI ${ }^{\dagger}$, DOKKA NARASIMHAM, YEDUGURI \\ HIMABINDU ${ }^{1,2}$, THAMMINENI CHAKRADHAR ${ }^{3}$, SHAIK NAZANEEN PARVEEN, MADHAVA C \\ REDDY $^{2}$, SOMAGOUNI SRINIVASA GOWD ${ }^{4}$, VANKARA ANU PRASANNA ${ }^{5}$ AND THUMMALA \\ CHANDRASEKHAR
}

\author{
Department of Environmental Science, Yogi Vemana University Kadapa- (A.P.)
}

Received: December, 2020; Revised accepted: March, 2021

\begin{abstract}
It is a well-known fact that heavy metal stress is one of the serious threats to agricultural yield. In the present work, heavy metal screening was carried out using chromium (Cr), lead ( $\mathrm{Pb}$ ) and manganese (Mn) independently on finger millet [Eleusine coracana (L.) Gaertn.] seed and seedling growth under in vitro conditions. Adverse effects of chromium on finger millet seed germination as well as seedling architectural damage were noticed from 10 ppm onwards. Particularly, 30 and $15 \%$ of seed germination was noticed at 50 and $100 \mathrm{ppm}$ concentrations of chromium, respectively. But the extremely toxic lead did not prove its toxic nature when compared to chromium and even at $100 \mathrm{ppm}$ concentration the reduction of seed germination and seedling growth were minor. Manganese promoted the seed germination even at 50 and 100 ppm concentrations. In ICP-OES (inductively coupled plasma-optical emission spectrometer) analysis, contents of residual nitrogen, phosphorous, potassium and sulphur were reduced in seedlings grown on media containing high concentrations of chromium which indicated the toxic levels of this particular metal in this crop. In addition, the sulphur content slightly increased in seedlings treated with higher concentration of lead and showed almost double amount in seedlings treated with high concentration of manganese. The contents of microelements varied with different treatments and as expected content of managense increased in seedlings treated with high concentration of manganese.
\end{abstract}

Keywords: Finger millet, chromium, lead, manganese, ICP-OES, growth, nutrient composition

\section{INTRODUCTION}

Heavy metal stress is one of the serious concerns, causing mostly adverse impacts on crop growth and development. Specifically, soil pollution has become a major threat for agriculture yield recently (Antoine et al., 2017). Inclusion of heavy metals in the soil leads to alteration in plant metabolic pathways including production of reactive oxygen species (ROS) which in turn damages the plant growth (Stambulska et al., 2018). Chromium is second most contaminant and seventh most abundant heavy metal in earth and is highly toxic in its valence state $\mathrm{Cr}(\mathrm{VI})$ when compared to $\mathrm{Cr}$ (III) state. Studies on the deleterious effect of chromium on different metabolic pathways were done in various crops such as pea, sunflower, rice, brassica etc. and found reduced yield levels (Ozdener et al., 2011; Ma et al., 2016). Similarly, lead is one of the major pollutants in soil and is more toxic than chromium. Lead is absorbed and accumulated in different parts of plants easily and regulated by $\mathrm{pH}$, calcium channels based on particle size and root exudation. Though $\mathrm{Pb}$ does not hold any biological worth, its accumulation may lead to decreased seed germination capacity, inhibition of chlorophyll biosynthesis and biomass, chromosomal lesions, root elongation etc., as observed previously in different plants (Chand et al., 2015; Wang et al., 2015). Essential manganese forms II, III and IV are found in biological systems and specifically form II is the most soluble one. In contrast, high accumulation of $\mathrm{Mn}$ in plants exhibits deleterious effects on photosynthesis and causes unfavorable growth (Anjum et al., 2015).

It is a well-known fact that finger millet is a nutritious food crop grown mostly for its grain and especially valuable as it contains the amino acid methionine besides rich sources of vitamin A, B1, B2 and B3 (Subastri et al., 2015). In addition, finger millet is an energy feed valuable for high carbohydrate content and considered as

${ }^{\star}$ Corresponding author E-mail: tcsbiotech@gmail.com/tcs@yogivemanauniversity.ac.in, ${ }^{2}$ Department of Biotechnology \& Bioinformatics, ${ }^{4}$ Department of Geology, ${ }^{5}$ Department of Zoology, Yogi Vemana University, Kadapa, ${ }^{3}$ Thakora Crop Sciences Pvt. Ltd, Anantapuramu- (A.P.) 
a helpful famine crop due to its easy storage. Further this crop serves as a best source of feed livestock and used in the production of liquors. Few research works conducted with finger millet using different heavy metals such as cobalt, mercury, zinc and cadmium and noticed the adverse impacts on seed germination along with callus growth in high concentrations (Krishania and Agarwal, 2015). The effects of various heavy metals such as $\mathrm{Cd}, \mathrm{Cr}, \mathrm{Co}, \mathrm{Pb}$ and $\mathrm{Sn}$ on seed germination and morphological and physiological variations in seedling growth in both pearl millet, green gram, great millet and horse gram crops have been reported by various workers (Gangaiah et al., 2013; Neelesh et al., 2014; Keerthi Kumari et al., 2016; Keerthi Kumari et al., 2017). Hence the present work was conducted to study the effect of heavy metal on finger millet seed germination and seedling growth and development.

\section{MATERIALS AND METHODS}

Initially, all the seeds of finger millet were washed in running tap water for 5 min to get them free from dust particles. Further surface sterilization of the seeds was carried out by treatment with $70 \%$ ethanol for $1 \mathrm{~min}$ and later treated with a solution of $0.1 \%$ mercuric chloride $\left[\mathrm{HgCl}_{2}(\mathrm{w} / \mathrm{v})\right]$ for $10 \mathrm{~min}$. Surface sterilization was followed by three rinses with sterile distilled water. Later the moist seeds were placed on sterile filter paper to remove excess moisture before inoculation into the respective medium.

\section{Media preparation and growth conditions}

The composition of the media includes distilled water along with 1, 10, 20, 30 (only for chromium), 50 and $100 \mathrm{ppm}$ concentrations of respective heavy metal i.e. $\mathrm{Cr}$ or $\mathrm{Pb}$ or $\mathrm{Mn}$ along with 0.8 percent agar. Media prepared with tap or distilled water (T.W. or D.W.) were used as controls without the inclusion of any metal. All the media were maintained at a $\mathrm{pH}$ of 5.8 and each test tube consisted of $15 \mathrm{ml}$ of medium. The sources of $\mathrm{Cr}, \mathrm{Pb}$ and $\mathrm{Mn}$ were potassium dichromate, lead nitrate and manganese sulphate monohydrate, respectively.

\section{Inoculation and in vitro growth conditions}

Culture tubes containing media were autoclaved at $15 \mathrm{lbs} / \mathrm{in}^{2}$ for $20 \mathrm{~min}$ in an autoclave and later inoculation of seed material was carried out in the laminar airflow chamber (LAF). The culture room was maintained at $25 \pm 2^{\circ} \mathrm{C}$ with a relative humidity of $50-60 \%$ in which incubation of inoculated test tubes was carried out along with 16 $\mathrm{h}$ photo period. All the data was collected on $15^{\text {th }}$ day (after two weeks) and a minimum of three replicates was involved in each experiment which was conducted thrice. Statistical part of the work i.e. the mean and standard error was done using standard excel program in the personal computer.

\section{ICP-OES analysis to estimate residual elements}

Determination of remnant elements from in vitro grown heavy metal treated seedlings along with untreated seedling materials was carried out using ICP-OES (Prodigy, Teledyne Leeman, Hudson, N.H., USA) through the modified method of Chen and Ma (2001).

\section{RESULTS AND DISCUSSION}

\section{Effect of Chromium}

The present study elevates the adverse impacts of $\mathrm{Cr}$ metal on finger millet seed germination and seedling growth (Fig. 1). About $90 \%$ of germination in both the controls and $80 \%$ in $1 \mathrm{ppm} \mathrm{Cr}$ medium was noticed when compared to germination at high concentrations. Seed germination and growth inhibition were observed from $10 \mathrm{ppm}$ concentration of chromium. Particularly, $30 \%$ and $15 \%$ of seed germination were observed at 50 and $100 \mathrm{ppm}$ of chromium (Fig. $1 \mathrm{~A}$ and $\mathrm{B}$ ). Hence, seedlings treated with 30 ppm were considered for various analyses due to lack of 50 and 100 ppm treated seedling materials. Length of both shoot and root was also affected with high doses of chromium. When compared to control, increasing chromium concentration from 1 to $100 \mathrm{ppm}$ exhibited decreased length of both shoots and roots (Fig. 1). Specifically, negligible root length values were noticed in seeds treated with high concentrations (Fig. 1 D). Thus, high concentration of chromium damages the seed germination and growth of finger millet seedlings but does not show any impact at low concentrations. These results also indicate that finger millet has the capacity to grow in chromium rich regions up to certain concentrations. Apart from seed germination, 
morphology of seedlings was also affected by chromium in different crops, specifically with respect to decline in shoot and root growth as noticed by Kabir (2016), Gangaiah et al. (2013) and Neelesh et al. (2014).

\section{Effect of Lead}

In lead treatment, unexpectedly there was a minor reduction in percentage of germination compared to control cultures (Fig. 1). In fact, minor increase in the seed germination at $50 \mathrm{ppm}$ and after that reduction in the percentage of germination at $100 \mathrm{ppm}$ was noticed. Similarly, negligible amount of reduction in the lengths of shoot and root at $100 \mathrm{ppm}$ concentration was observed (Fig. 1). There were uneven modifications in shoot and root lengths occurred with lead but overall there was no much toxic effect was noticed (Fig. 1). Generally, toxic symptoms of lead such as stunted growth, blackening of root system, chlorosis etc., were not observed in the present work. Moreover, an increasing pattern of seed germination at $50 \mathrm{ppm}$ of $\mathrm{Pb}$ (Fig. 1) indicates that this crop has tolerance to lead.

A
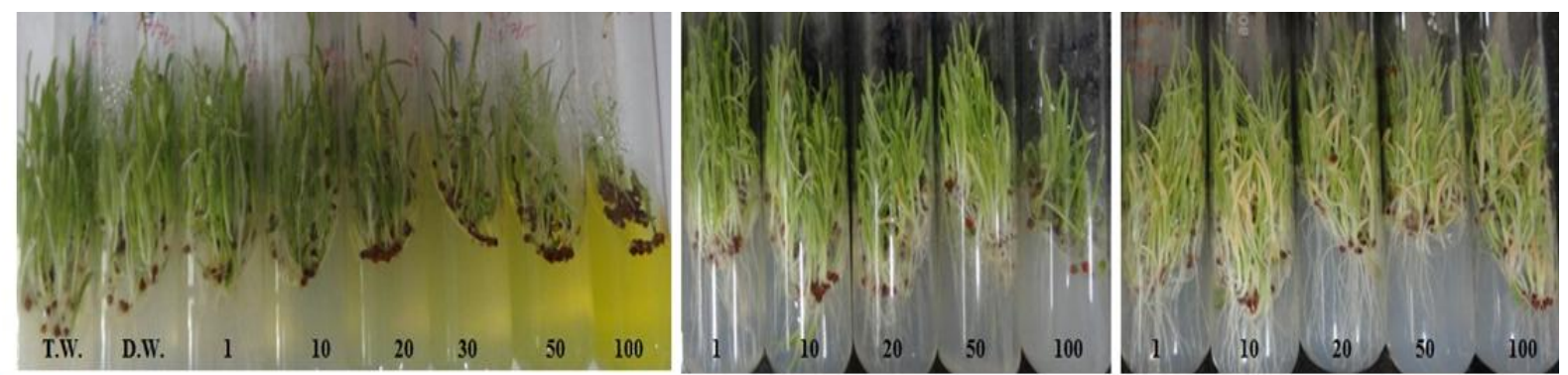

B
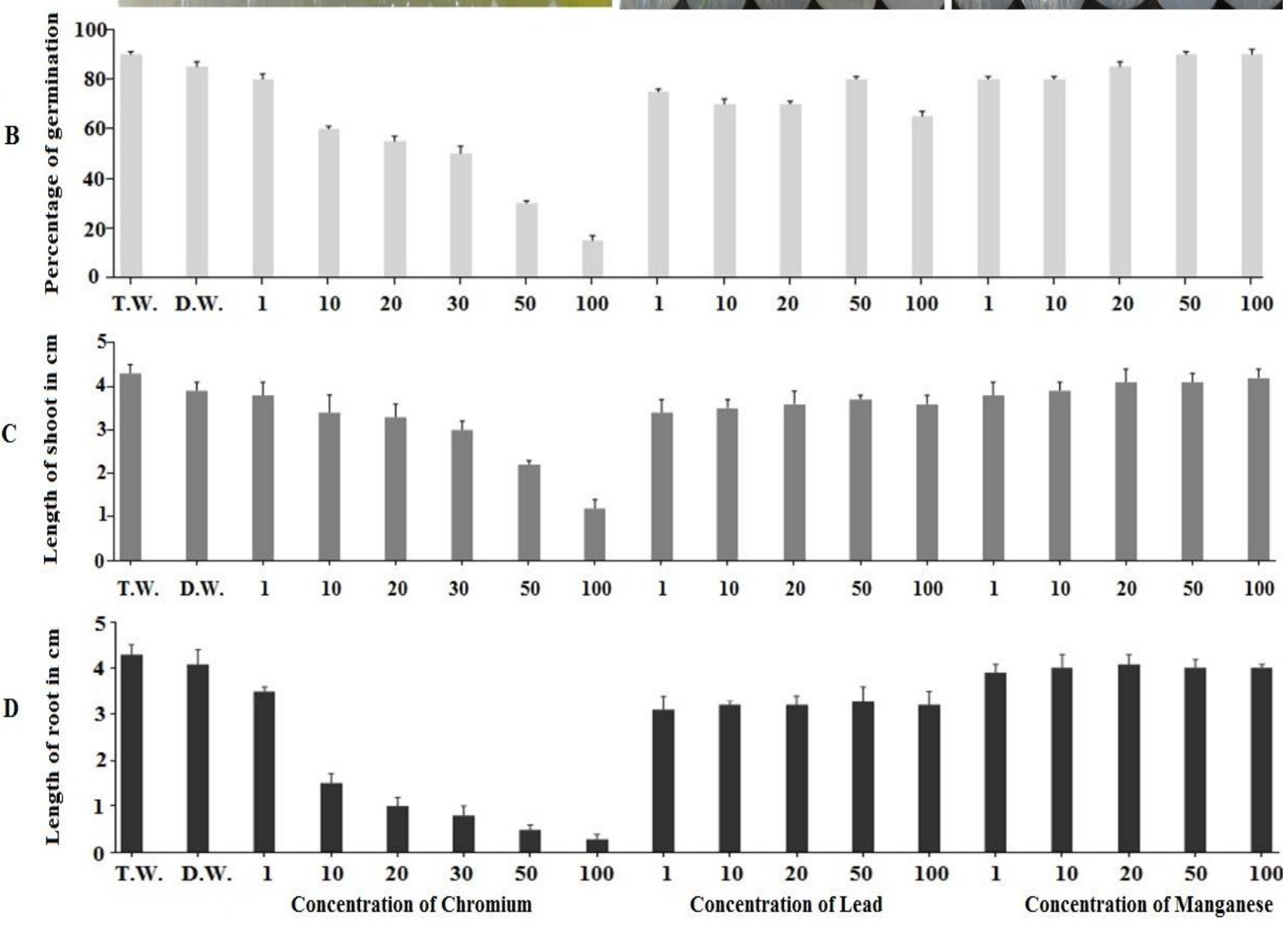

Fig.1: Effect of chromium, lead and manganese on seed germination and seedling growth of finger millet 


\section{Effect of Manganese}

Gradual promotion in seed germination and seedling growth with increasing $\mathrm{Mn}$ concentrations was observed (Fig. 1). Percentage of germination was high in all the treatments ranging from 80 to 90 which are almost equal to controls. Moreover, increasing $\mathrm{Mn}$ concentration exhibited increase in length of shoot in our investigation (Fig. 1). Morphology of all the manganese treated seedlings was almost same, indicating the growth promoting nature of manganese in this crop. In contrast, number of roots were slightly reduced in samples under high concentration of manganese (Fig. 1). Any phytotoxic nature even in excess concentrations (excluding minor root variation) was not observed with $\mathrm{Mn}$ in this crop. In contrast, excess of manganese causes reduction in the seedling growth in horse gram was noticed (Keerthi Kumari et al., 2016). High concentration of $\mathrm{Mn}$ in plant tissue causes alterations in enzyme activity, absorption and mineral elements usage indicated that the finger millet has ability to grow in these heavy metal rich areas.

Table 1: Effect of heavy metals on contents (\%) of macroelements in seedlings using ICP-OES analysis

\begin{tabular}{|c|c|c|c|c|c|c|c|c|c|c|c|c|c|c|c|c|c|}
\hline \multirow[t]{2}{*}{ Elements } & Controls & \multicolumn{6}{|c|}{$\begin{array}{c}\text { Seedling on } \\
\text { Cr medium (ppm) }\end{array}$} & \multicolumn{5}{|c|}{$\begin{array}{c}\text { Seedling on } \\
\text { Pb medium (ppm) }\end{array}$} & \multicolumn{5}{|c|}{$\begin{array}{c}\text { Seedling on } \\
\text { Mn medium (ppm) }\end{array}$} \\
\hline & \begin{tabular}{|l|l|} 
T.W & D.W \\
\end{tabular} & 1 & 10 & 20 & 30 & 50 & 100 & 1 & 10 & 20 & 50 & 100 & 1 & 10 & 20 & 50 & 100 \\
\hline $\mathrm{N}$ & $2.6 \quad 2.6$ & 2.7 & 2.6 & 2.6 & 2.4 & & & & & & & & & & & & \\
\hline $\mathrm{P}$ & $0.82 \quad 0.78$ & 0.96 & 0.76 & 0.74 & & & & 1.45 & 1.42 & 1.4 & 1.36 & 1.28 & 1.29 & 1.33 & 1.35 & 1.29 & 1.3 \\
\hline K & $2.4 \quad 2.2$ & 2.5 & 1.9 & 1.9 & & & & 1.41 & 1.40 & 1.42 & 1.51 & 1.59 & 1.76 & 1.74 & 1.68 & 1.83 & 1.82 \\
\hline S & 0.630 .59 & 0.62 & 0.48 & 0.44 & & & & 0.29 & 0.29 & 0.29 & 0.29 & 0.30 & 0.32 & 0.39 & 0.44 & 0.49 & 0.59 \\
\hline
\end{tabular}

\section{ICP-OES analysis Macroelements}

Negligible difference in nitrogen contents between controls (2.6) and $1 \mathrm{ppm}$ chromium treated seedlings (2.7) was noticed (Table 1). Also minor reduction of nitrogen content from 1 to $30 \mathrm{ppm}$ was observed, which indicates the essentiality of this macronutrient in seedling growth and development. Residual phosphorus and potassium contents were reduced with increasing concentration of chromium due to damage caused by this heavy metal. Uneven phosphorus and potassium values were observed in lead and manganese treated seedlings. Overall, content of phosphorous was more and content of potassium was less when compared to control seedlings. Significant decrease of sulphur was observed in chromium treatment and it may be attributed to the breakage of protein bonding and less sulphur will be absorbed from the limited air due to severe damage of seedlings. In addition, gradual increase in sulphur content was noticed with increased $\mathrm{Mn}$ concentration in the medium. Overall, the most significant observation in ICPOES analysis is that chromium treated seedlings differ from lead and manganese treated seedlings with respect to the contents of residual macroelements (Table 1). Particularly, macroelements are reduced with increasing chromium concentration due to severe noxious nature of this particular metal with this crop. This damage probably releases these elements from the plant and sent in to the environment. These results correlated with the report of Shobana et al. (2013) that generally among millets, finger millet contains more macroelements but $\mathrm{Cr}$ treatment reduces the levels to some extent indicating the toxic effect of this particular heavy metal. Irregular macroelement values (except sulphur) were observed in lead and manganese treated seedlings.

\section{Microelements}

Contents of $\mathrm{Fe}$ in chromium treated seedlings were progressively increased from 1 $\mathrm{ppm}$ to $20 \mathrm{ppm}$ and uneven values were observed in lead and manganese treated seedlings (Table 2). In agreement with these results, increasing chromium concentration increases iron levels and this may be function less iron as per Singh etal. (2011). Zinc content 
Table 2: Effect of heavy metals on contents (ppm) of microelements in seedlings using ICP-OES analysis

\begin{tabular}{|c|c|c|c|c|c|c|c|c|c|c|c|c|c|c|c|c|c|c|}
\hline \multirow{2}{*}{ Elements } & \multicolumn{2}{|c|}{ Controls } & \multicolumn{6}{|c|}{$\begin{array}{c}\text { Seedling on } \\
\text { Cr medium (ppm) }\end{array}$} & \multicolumn{5}{|c|}{$\begin{array}{c}\text { Seedling on } \\
\mathrm{Pb} \text { medium (ppm) }\end{array}$} & \multicolumn{5}{|c|}{$\begin{array}{c}\text { Seedling on } \\
\text { Mn medium (ppm) }\end{array}$} \\
\hline & T.W & 5 & 1 & 10 & 20 & 30 & 50 & 100 & 1 & 10 & 20 & 50 & 100 & 1 & 10 & 20 & 50 & 100 \\
\hline $\mathrm{Fe}$ & 118.6 & 7 & 75.7 & 86.3 & 107 & & & & 78 & 93 & 96 & 84 & 88 & 97 & 98 & 86 & 76 & 80 \\
\hline$\angle r$ & 38 & 36.5 & 42.8 & 37.3 & 38.3 & & & & & 41.07 & 41.12 & 39.48 & 40.27 & 47.48 & 47.14 & 46.74 & 46.8 & 46.9 \\
\hline $\mathrm{Cu}$ & 32.9 & 31.6 & 33.7 & 32.8 & 32 & & & & 8 & 12.58 & 15.26 & 13.32 & 12 & & 17.6 & 16.44 & 14.1 & 15.76 \\
\hline $\mathrm{Mn}$ & 366.2 & 394.9 & 459 & 350.9 & 264.8 & & & & 159 & 150 & 157 & 258 & 131 & 376 & 1281 & 2182 & 3519 & 5083 \\
\hline
\end{tabular}

in chromium treated seedlings was uneven but overall content was more in $\mathrm{Pb}$ and $\mathrm{Mn}$ treatments when compared to control seedlings. Overall, copper values decreased in lead and manganese treated seedlings when compared to controls. As expected manganese values were increased in $\mathrm{Mn}$ treated seedlings and were decreased in high $\mathrm{Cr}$ treated seedlings. Decreased copper and manganese values in high chromium treatments may be due to their release from the seedlings because of high toxicity. Particularly increased manganese in $\mathrm{Mn}$ treatments is not surprise in the present work.

Among heavy metals used in the present investigation, chromium proved to be more toxic than lead and manganese promoted the seed germination as well growth of the seedlings under in vitro conditions. Specifically, only 30\% and $15 \%$ of seed germination was achieved at 50 and 100 ppm chromium concentrations. Similarly, both shoot and root lengths were also

\section{REFERENCES}

Anjum, N.A., Singh, H.P., Khan, M.I., Masood, A., Per, T.S, Negi, A., Batish, D.R., Khan, N.A., Duarte, A.C., Pereira, E. and Ahmad, I. (2015) Too much is bad-an appraisal of phytotoxicity of elevated plant-beneficial heavy metal ions. Environmental Science and Pollution Research 22: 3361-3382.

Antoine, J.M., Fung, L.A. and Grant, C.N. (2017) Assessment of the potential health risks associated with the aluminium, arsenic, cadmium and lead content in selected fruits and vegetables grown in Jamaica. Toxicology Reports 4: 181-187.

Chand, S., Yaseen, M., Rajkumari. and Patra, D.D. (2015) Application of heavy metal rich tannery sludge on sustainable reduced in seedlings grown on high concentration of chromium and particularly lengths of roots were drastically decreased. Moreover, there was minor reduction with respect to percentage of seed germination and seedling growth even at $100 \mathrm{ppm}$ concentration of lead. Manganese promoted the seed germination and seedling growth even in high doses with negligible errors. In ICP-OES data, content of remnant macronutrients were reduced in seedlings grown on high chromium concentration media indicates the lethal nature of this metal in this crop. Furthermore, this work may be useful to deal with the various morphological, biochemical and molecular insights of heavy metal stress on crop plants and outline the scope for future research.

\section{ACKNOWLEDGEMENTS}

The authors are grateful to the AgriScience Project, Ministry of Industries and Commerce, Government of Andhra Pradesh, India for financial support to TCS.

growth, yield and metal accumulation by clarysage (Salvia sclarea L.). International Journal of Phytoremediation 17: 1171-1176.

Chen, M. and Ma, L.Q. (2001) Comparison of three aqua regia digestion methods for twenty Florida soils. Soil Science Society of America Journal 65: 491-499.

Gangaiah, A., Chandrasekhar, T., Varaprasad, D., Hima Bindu, Y., Keerthi Kumari, M., Chakradhar, T. and Madhava Reddy, C. (2013) Effects of heavy metals on in vitro seed germination and early seedling growth of Pennisetum glaucum (L.) R.Br. International Journal of Food Agriculture and Veterinary Science 3: 87-93. 
Kabir, A.H. (2016) Biochemical and molecular changes in rice seedlings (Oryza sativa L.) to cope with chromium stress. Plant Biology 18: 710-719.

Keerthi Kumari, M., Varaprasad, D., Narasimham, D., Paramesh, K. and Chandrasekhar, T. (2016) Impacts of cadmium and manganese on in vitro seed germination and seedling growth of horsegram. Indian Journal of Plant Science 5: 119-125.

Keerthi Kumari, M., Varaprasad, D., Paramesh, K., Narasimham, D., Raga Sudha, N., Himabindu, Y. and Chandrasekhar, T. (2017) Toxic effects of cadmium on in vitro seed germination and seedling growth of Sorghum bicolor (L.) Moench. International Journal of Innovative Pharmaceutical Sciences Research 5: 126-135.

Krishania, S. and Agarwal, K. (2013) Effects of heavy metalsstress on callus induction and regeneration of finger millet (Eleusine coracana) (L.) Gaertn. Research Journal of Recent Sciences 2: 24-48.

Ma, J., Lv, C., Xu, M., Chen, G., Lv, C. and Gao, Z. (2016) Photosynthesis performance, antioxidant enzymes, and ultrastructural analyses of rice seedlings under chromium stress. Environental Science and Pollution Research 23: 1768-1778

Neelesh Babu, T., Varaprasad, D., Hima Bindu, Y., Keerthi Kumari, M., Dakshayani, L., Madhava Reddy, C. and Chandrasekhar, T. (2014) Impactof heavy metals (Cr, Pb and $\mathrm{Sn}$ ) on in vitro seed germination and seedling growth of green gram (Vigna radiata (L.) R. Wilczek). Current Trends in Biotechnology and Pharmacy 8: 160165.

Ozdener, Y., Aydin, B.K., Aygün, S.F. and Yürekli, F. (2011) Effect of hexavalent chromium on the growth and physiological and biochemical parameters on Brassica oleracea L. var. acephala DC. Acta Biologica Hungarica 62: 463-476.

Shobana, S., Krishnaswamy, K., Sudha, V., Malleshi, N.G., Anjana, R.M., Palaniappan, L. and Mohan, V. (2013) Finger millet (Ragi, Eleusine coracana L.): A review of its nutritional properties, processing, and plausible health benefits. Advances in Food and Nutrition Research 69: 1-39.

Singh, R., Gautam, N., Mishra, A. and Gupta, R. (2011) Heavy metals and living systems: An overview. Indian Journal of Pharmacology 43: 246-253.

Stambulska, U.Y., Bayliak, M.M. and Lushchak, V.I. (2018) Chromium (VI) toxicity in legume plants: modulation effects of rhizobial symbiosis. BioMed Research International 80312-80313.

Subastri, A., Ramamurthy, C., Suyavaran, A., Mareeswaran, R., Mandal, P., Rellegadla, S. and Thirunavukkarasu, C. (2015) Nutrient profile of porridge made from Eleusine coracana (L.) grains: effect of germination and fermentation. Journal of Food Science and Technology 52: 6024-6030.

Wang, Y., Shen, H., Xu, L., Zhu, X., Li, C., Zhang, W., Xie, Y., Gong, Y. and Liu. L. (2015) Transport, ultrastructural localization, and distribution of chemical forms of lead in radish (Raphanus sativus L.). Frontierrs in Plant Sciences 6: 293. 